\title{
Hybrid Peripheral Revascularizations
}

\author{
Martin Maresch* and Jamal Hashem \\ Vascular \& Endovascular Surgeon, Bdf Hospital-Royal Medical Services, Bahrain
}

Submission: March 03, 2017; Published: May 08, 2017

*Corresponding author: Martin Maresch, Vascular \& Endovascular Surgeon, Bdf Hospital-Royal Medical Services, Bahrain, Email: matomar11@yahoo.com

Keywords: Critical limb ischemia; Endovascular treatment; Hybrid procedure

\section{Introduction}

In the continuously evolving efforts to provide optimum revascularization for high risk Critical Limb Ischemia patients, vascular surgeons around the world have widely adopted hybrid approach. This combination of the advantages of open and endovascular techniques allows the implementation of tailored complex multi-level reconstruction plans usually within a single setting [1-3].

What started over 40 years ago, with the combination of simple iliac angioplasty and femoro-femoral bypass [4] is gradually increasing in complexity \& becoming a widely accepted therapeutic option. Furthermore, the increasing sophistication of minimally invasive endovascular techniques with successful treatment of multi-segmental lesions has contributed to a reduced morbidity \& duration of hospital stay when Hybrid revascularizations are performed [5]. The final benefit thus is full revascularization of the target arterial bed with an acceptable risk.

Gaps \& Inconsistencies in literature on hybrid procedures stem partially from the variable clinical presentations, timing of hybrid reconstruction (single setting vs. stages) and the wide range of open surgical \& endovascular approaches adopted. In addition to the above, definitions \& terminology vary between centers making comparison very difficult $[1,2,6]$. Further research into the area is definitely needed, however the available literature suggests promising outcomes, comparable in efficacy to the current standards of care. This is increasingly important as a significant proportion of patients require multiple revascularizations to prolong amputation free survival and hence require ever evolving creative solutions $[5,7]$.

At the center of these procedures is the dissection of the femoral artery and its bifurcation. Hence, depending on the case open endarterectomy \& patch angioplasty is performed, or it is employed as the inflow for a femoro-distal reconstruction. It is quite likely that in the next few years technological advancement may result in single endovascular solutions. But as the current literature stands though, the results of Common Femoral Artery open endarterectomy with autogenous angioplasty are superior in terms of durability to available endovascular options. [8] Femoro-Popliteal or Femoro-Distal bypasses are used either as an alternative to long segment SFA CTO Endovascular treatment or as a last resort following in-stent occlusions. Tibial and Pedal angioplasty might be required concomitantly in more complex cases to improve the distal run off \& prevent early thrombosis, \& has shown good results $[9,10]$.

Higher incidence of post-operative bleeding can be expected due to continuous anti platelets and the higher doses of heparin used during and after the procedures. It is advisable to avoid the use of prosthetic materials whenever possible due to their association with an increased risk of postoperative wound infections. In part this is due to the vascular risk factors and other patient co-morbidities which result in immuno-compromise and delayed wound healing, in addition to the high incidence of existing infection within the patient's ulcer or gangrenous lesion.

\section{Case Report}

A 64 years old male teacher, known case of accelerated atherosclerosis and uncontrolled diabetes mellitus, hypertension, Ischemic heart disease (post CABG). The patient was also suffering from peripheral arterial disease manifesting as short-distance left lower limb claudication for which he underwent multiple endovascular interventions by an invasive cardiologist over the last two years. Consequently, the patient 
ended up with a total of 7 implanted along the entire course of his Left SFA.

He presented to our A/E department complaining from severe left foot rest pain resistant to analgesia. On examination, the patient had a +1 femoral pulse with absent popliteal \& distal pulses. The foot was cold with absent dorsalis pedis Doppler signals, monophasic posterior tibial signals and an incompressible ABI.

Following routine laboratory investigations, optimization \& nephro-protective agents the patient was taken to the operating theatre. Initial access was done with a $6 \mathrm{Fr}$ sheath inserted retrogradely into the right CFA. Diagnostic angiography revealed significant stenosis with heavy calcification at the ostiun of bilateral iliac arteries, complete instent occlusion of the Left SFA and a single vessel run off with multiple stenotic segments within the posterior tibial artery \& complete occlusion of anterior tibial \& peroneal arteries. Dissection of the Left Femoral Bifurcation, distal Popliteal Artery and Ipsilateral GSV harvesting were performed prior to the administration of heparin. Hence an 8000 IU Bolus of unfractionated heparin was given intravenously and a $6 \mathrm{Fr}$ sheath was inserted retrogradely into the left common femoral artery (Figure 1).

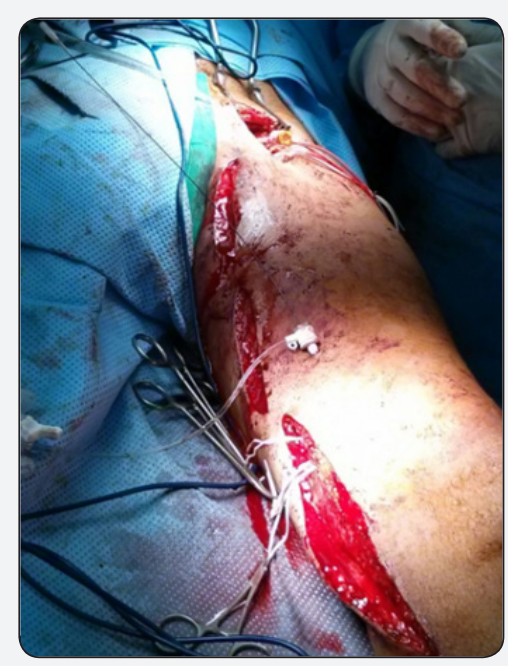

Figure 1: Dissection of the Left Femoral Bifurcation, distal Popliteal Artery and Ipsilateral GSV harvesting were performed and a $6 \mathrm{Fr}$ sheath was inserted retrogradely into the left common femoral artery.

Recanalization of the inflow and deployment of kissing $9 \mathrm{~mm}$ balloon expandable stents was done at the ostia of the Common Iliac arteries with restoration of a good inflow. Autovenous reverse Femoro-Popliteal bypass was performed in standard fashion. $4 \mathrm{Fr}$ sheath was then inserted into the distal segment of the bypass in antegrade fassion. Angioplasty of tibioperoneal trunk and posterior tibial artery with reconstruction of pedal arch was performed as the final component of the treatment to improve outflow and prevent early thrombosis of the bypass.
The procedure was done in epidural anesthesia with minimal sedation and the patient remained hemodynamically stable throughout the surgery.

His post-operative course was uneventful with resolution of rest pain, mobilization on the 2 nd post operative day \& was discharged walking on the 7 th post operative day. The patient continues to follow up in the outpatient clinic \& does not currently complain of intermittent claudication or rest pain.

\section{Conclusion}

Multilevel atherosclerotic arterial disease affecting the lower extremities requires complex treatment strategies involving inflow and outflow arterial reconstructions to prolong amputation free-survival \& allow healing of defects. Multi-segmental arterial disease is frequently associated with significant co-morbidities and patients presenting with critical Limb Ischemia are typically high risk for major operative procedures. Hybrid procedures combining benefits of open reconstructions and endovascular techniques enable multilevel revascularizations in high-risk CLI patients with favorable patency and limb salvage and currently comprise $15 \%$ of all revascularizations done at our center, with increasing popularity worldwide. Dissection of femoral artery plays a central role. For selected groups of patient is Hybrid approach not only the best solution but the only one possible.

\section{References}

1. Nelson PR, Powell RJ, Schermerhorn ML, Fillinger MF, Zwolak RM, et al. (2002) Early results of external iliac artery stenting combined with common femoral artery endarterectomy. J Vasc Surg 35(6): 1107-1113.

2. Cotroneo AR, Iezzi R, Marano G, Fonio P, Nessi F, et al. (2007) Hybrid therapy in patients with complex peripheral multifocal stenoobstructive vascular disease: two-year results. Cardiovasc Intervent Radiol 30(3): 355-361.

3. Cynamon J, Marin ML, Veith FJ, Bakal CW, Wahl SI, et al. (1997) Stentgraft repair of aorto-iliac occlusive disease coexisting with common femoral artery disease. J Vasc Interv Radiol 8(1 Pt 1): 19-26.

4. Porter JM, Eidemiller LR, Dotter CT, Rösch J, Vetto RM (1973) Combined arterial dilatation and femorofemoral bypass for limb salvage. Surg Gynecol obstet 137(3): 409-412.

5. Zhou M, Huang D, Liu C, Liu Z, Zhang M, et al. (2014) Comparison of hybrid procedure and open surgical revascularization for multilevel infrainguinal arterial occlusive disease. Clin Interv Aging 22(9): 15951603.

6. Dosluoglu HH, Cherr GS (2006) Pre-arteriotomy guidewire access (PAGA). A crucial maneuver for securing inflow and/or outflow in patients with bulky iliofemoral occlusive disease undergoing combined (open/endovascular) procedures. Eur J Vasc Endovasc Surg 32(1): 97-100.

7. Bradbury A, Adam D, Bell J, Forbes JF, Fowkes R, et al. (2010) Bypass versus Angioplasty in Severe Ischaemia of the Leg (BASIL) trial: An intention-to-treat analysis of amputation-free and overall survival in patients randomized to a bypass surgery-first or a balloon angioplastyfirst revascularization strategy. J Vasc Surg 51(5 Suppl): 5S-17S.

8. Bonvini RF, Rastan A, Sixt S, Noory E, Schwarz T, et al. (2011) Endovascular treatment of common femoral artery disease: medium- 
term outcomes of 360 consecutive procedures. J Am Coll Cardiol 58(8): 792-798.

9. Ambler G, Stimpson A, Wardle B, Bosanquet D, Hanif U, et al. (2017) Infrapopliteal angioplasty using a combined angiosomal reperfusion strategy. Plos One 12(12): e0172023.

This work is licensed under Creative Commons Attribution 4.0 License

DOI: 10.19080/JOCCT.2017.05.555657
10. Wagdya W, Othmanc M, Saluzzob C, Abdallah A (2016) Role of infrapopliteal angioplasty in diabetic and non-diabetic patients. The Egyptian Journal of Radiology and Nuclear Medicine 47(3): 853-858.

\section{Your next submission with Juniper Publishers will reach you the below assets}

- Quality Editorial service

- Swift Peer Review

- Reprints availability

- E-prints Service

- Manuscript Podcast for convenient understanding

- Global attainment for your research

- Manuscript accessibility in different formats ( Pdf, E-pub, Full Text, Audio)

- Unceasing customer service

Track the below URL for one-step submission https://juniperpublishers.com/online-submission.php 